\title{
Body condition loss during the dry period: Insights from feeding behavior studies
}

\author{
Ruan R. Daros, ${ }^{1,2}$ (1) Casey D. Havekes, ${ }^{3}$ and Trevor J. DeVries ${ }^{3 *}$ () \\ ${ }^{1}$ Animal Welfare Program, Faculty of Land and Food Systems, University of British Columbia, Vancouver, British Columbia V6T 1Z4, Canada \\ ${ }^{2}$ Graduate Program in Animal Science, School of Life Sciences, Pontifícia Universidade Católica do Paraná (PUCPR), Curitiba, \\ Paraná 80215-901, Brazil \\ ${ }^{3}$ Department of Animal Biosciences, University of Guelph, Guelph, Ontario N1G 2W1, Canada
}

\begin{abstract}
Body condition change during the dry period ( $\triangle \mathrm{BCS}$ ) has been associated with a myriad of transition cow diseases. We used data from 3 studies to assess the relationship between $\triangle \mathrm{BCS}$, feeding behavior, and body condition score (BCS) at dry-off. We also studied the mediation effect that dry matter intake (DMI) has on $\triangle \mathrm{BCS}$ and the association between dry period feeding time and DMI. A total of 100 parous cows were enrolled in 3 studies to investigate differences in dry period diet on behavior, health, and performance preand postcalving. Body weight was measured and BCS was assessed by the same trained observer after dry-off and $1 \mathrm{wk}$ from calving date. The $\triangle \mathrm{BCS}$ was calculated by subtracting the BCS at calving minus the BCS at dry-off. The BCS at dry-off was categorized as overconditioned $(\geq 3.5)$ or not overconditioned $(<3.5)$; no cows had a BCS $<2.75$. Feeding behavior data were collected using electronic feed bins. Parity at dry-off (median $=2 ; \min =1, \max =6)$ and $305-\mathrm{d}$ milk production $($ mean $=10,235 \mathrm{~kg}, \mathrm{SD}=1,625 \mathrm{~kg})$ from the previous lactation were considered. Data sets were split into 2 time periods: $\mathrm{d}-56$ to -22 (early) and -21 to 0 (late) in relation to calving. Selected feeding behaviors (DMI, DMI as a percentage of body weight, and feeding time) were used to evaluate the associations between each feeding behavior and BCS at dry-off in each period using mixed linear regression models. Each model included the following covariates: parity, previous 305-d milk yield, and trial treatment. Experimental day was included as random slope, and cow was included as random intercept. A mediation analysis was used to evaluate the potential causal direct effect of BCS at dry-off on $\triangle \mathrm{BCS}$ and the potential indirect effect mediated by differences in DMI. The BCS at dry-off was associated with changes in feeding behavior, such that overcon-
\end{abstract}

Received August 14, 2020.

Accepted November 25, 2020.

*Corresponding author: tdevries@uoguelph.ca ditioned cows had lesser daily DMI and feeding time during the early and late dry periods compared with not overconditioned animals. We also noted an effect of previous 305-d milk yield on DMI; cows that produced more milk had greater DMI throughout the dry period. The $\triangle \mathrm{BCS}$ was only partially mediated by DMI, and BCS at dry-off still had a direct effect on $\triangle \mathrm{BCS}$. This result indicated that mechanisms other than DMI were associated with BCS loss during the dry period. Feeding time correlated weakly and moderately with DMI during the early and late dry periods, respectively. To conclude, strategies to improve intake during the dry period should take dry-off BCS into account or, preferably, efforts should be made to minimize the number of overconditioned cows at the end of lactation.

Key words: mediation analysis, body condition loss, dairy cattle, transition-period diseases

\section{INTRODUCTION}

Body condition loss during the dry period and into the early postpartum period has been associated with increased odds of cows developing metabolic and infectious diseases after calving (Kaufman et al., 2016; Chebel et al., 2018). Cows that have greater BCS at the end of the lactation are, invariably, the cows that lose more condition in the precalving period, and underconditioned cows tend to gain or maintain body condition during the dry period (Chebel et al., 2018; Daros et al., 2020). There is a lack of research on the association of BCS at dry-off with feeding behavior (including DMI and feeding time) of dry cows, especially in the weeks following dry-off. Studies evaluating the association between BCS at dry-off and feeding behavior may support changes in the management of dry cows and increase our understanding about the relationship between feeding behavior and body condition change during the dry period $(\triangle \mathrm{BCS})$.

It has been proposed that lipolysis, at least during the early lactation period, is largely controlled by homeorhetic mechanisms rather than environmental 
ones, such as feed availability and intake (see review by Roche et al., 2009). Hence, it is reasonable to assume that homeorhetic mechanisms are involved in lipid mobilization during the precalving period (Ghaffari et al., 2019; Schuh et al., 2019). Nonetheless, several researchers have described DMI patterns during the transition period (see review by Grummer et al., 2004), and some have demonstrated that overconditioned cows have reduced DMI in the month before calving (Hayirli et al., 2002; Schuh et al., 2019). However, to date, no researchers have associated DMI with $\triangle \mathrm{BCS}$.

We propose using a mediation analysis to understand the interplay between DMI and $\triangle \mathrm{BCS}$. Mediation analysis may be applied to longitudinal observational data to disentangle mechanisms of cause-effect, given that the models used represent a plausible biological rationale (Pearl, 2019). In this analysis, we proposed that DMI mediates the causal relationship between BCS at dry-off and $\triangle B C S$. Specifically, we predicted that overconditioned cows would eat less during the dry period, resulting in greater body condition loss during this time period. In this case, DMI is the feeding behavior variable most likely to be related to $\triangle \mathrm{BCS}$ because the accumulation of fat is a function of nutrient intake and its metabolism.

Longitudinal feeding behavior studies allow for assessing correlation between behavior over different physiological phases; for example, feeding time correlates with DMI during the lactation period (Johnston and DeVries, 2018). It is of interest to determine if this association holds over the nonlactating period as cameras or other automatic monitors may be used to assess feeding time (e.g., Daros et al., 2020), but it is impossible to collect individual DMI data for grouphoused cows on commercial farms. To our knowledge, there are few studies that report on the association between feeding time and DMI during the dry period (e.g., Huzzey et al., 2007), although such studies only explored this association in the transition period ( -3 to +3 wk in relation to calving).

Thus, the objectives of this study were 3 -fold: (1) to describe the associations between BCS at dry-off with selected feeding behaviors during the dry period, (2) to assess the potential causal relationship between DMI and $\triangle \mathrm{BCS}$ in the dry period, and (3) to verify the association between DMI and feeding time over the dry period.

\section{MATERIALS AND METHODS}

The data used for this study were previously collected for 3 separate projects (Havekes et al., 2020a,b,c). All studies and their procedures were approved by the University of Guelph Animal Care Committee (protocol
\#3628). Detailed description of these studies and their methodology are found in Havekes et al. (2020a,b,c). In brief, at the time of dry-off ( $\sim 45 \mathrm{~d}$ from calving), a total of 100 parous Holstein cows housed at the University of Guelph Elora Research Centre-Dairy Facility (Elora, Ontario, Canada) were enrolled in research projects focused on the effect of dry period diets on behavior, health, and performance. Cows were dried off using the research farm's dry-off protocol. The protocol involved abrupt dry-off (cessation of milking) for any cows producing $\leq 22 \mathrm{~kg} / \mathrm{d}$, and cows producing $\geq 23$ $\mathrm{kg} / \mathrm{d}$ were milked once per day and fed their respective dry-cow diet for $4 \mathrm{~d}$ before dry-off. At dry-off, all cows received dry-cow antibiotic treatment (cloxacillin benzathine; Dry-Clox, Boehringer Ingelheim Animal Health Canada Inc., Burlington, ON, Canada). Cows were followed from dry-off to $28 \mathrm{~d}$ postcalving. The BW and BCS measurements were taken immediately after dry-off, and then weekly from dry-off to calving for 40 cows from 1 trial, and 7 and $14 \mathrm{~d}$ before calving for 60 cows from the other 2 trials. The same trained observer recorded BCS for all cows using the methodology described by Wildman et al. (1982), where 1 = severely underconditioned to $5=$ severely overconditioned, with scores around 3 generally accepted as good condition in dairy cows (for further details, see Roche et al., 2009). Before the study, the observer undertook training with a secondary individual to ensure consistent methodology. In brief, the observer was first trained with resources from Elanco Animal Health (1997), after which the observer assessed a subset of cows from another study with the secondary individual to reinforce scoring uniformity between observers. Finally, interobserver reliability between those 2 individuals was evaluated by comparing BCS from another subset of cows assessed independently (kappa $=0.85)$.

All cows were kept in freestall pens fitted with electronic feed bins (Insentec, B.V., Marknesse, the Netherlands); stocking density at the feed bunk and stalls never exceeded $100 \%$ (i.e., cows had free access to at least 1 lying stall and 1 feed bin at any given time). Cows were trained to eat of out individually assigned feed bins.

Across studies, cows were assigned to 1 of 5 precalving diets $(\mathrm{n}=20$ per diet), all offered ad libitum from dry-off to calving. Forty cows had access to a similar high-straw dry-cow TMR diet (Havekes et al., 2020a) formulated to target an energy consumption of 19 $\mathrm{Mcal} /$ cow per day of $\mathrm{NE}_{\mathrm{L}}$, a negative $\mathrm{DCAD}$ value of $-245 \mathrm{mEq} / \mathrm{kg}$, and a chloride level of $1.1 \%$ (DM basis). For half of the group (20 cows), the straw in the diet was chopped with a $2.54-\mathrm{cm}$ screen, and the other half of cows received straw in their diet that was chopped with a 10.16-cm screen (Havekes et al., 2020a). Sixty 
cows had access to a basal high-straw dry-cow TMR diet (Havekes et al., 2020b,c) formulated to target an energy consumption of $20.8 \mathrm{Mcal} / \mathrm{cow}$ per day of $\mathrm{NE}_{\mathrm{L}}$, a negative DCAD value of $-176 \mathrm{mEq} / \mathrm{kg}$, and a chloride level of $0.83 \%$ (DM basis). From that group, 20 cows received the diet as described. Another 20 cows received, in addition to the basal diet, $1.0 \mathrm{~kg} / \mathrm{cow}$ per day (DM basis) of molasses-based liquid supplement, targeting an energy consumption of $22.9 \mathrm{Mcal} / \mathrm{cow}$ per day of $\mathrm{NE}_{\mathrm{L}}$ (Havekes et al., 2020c). The other 20 cows had water added to their dry-cow TMR to reduce the ration DM by $\sim 10 \%$ compared with the basal diet (Havekes et al., 2020b).

\section{Feeding Behavior and Data Handling}

Behavioral data were electronically collected using Insentec feed bins, previously validated by Chapinal et al. (2007). Dry matter intake, feeding time, feeding rate, meal frequency, meal size, meal length, and interval between meals were summarized per cow per day (Table 1). Dry matter intake was further controlled for by accounting for differences in BW and expressed as DMI as a percentage of BW (DMI\%BW). Meal criteria were calculated as described by DeVries et al. (2003), and from this measurement, all other mealrelated behaviors were derived (see Havekes et al., 2020a,b,c).

The $\triangle \mathrm{BCS}$ was calculated as the BCS at calving minus the BCS at dry-off; thus, negative $\triangle \mathrm{BCS}$ meant cows lost BCS, and a positive $\triangle \mathrm{BCS}$ meant that cows gained BCS during the dry period. Body condition score at dry-off was further categorized into not overconditioned (BCS $<3.5$ ) and overconditioned (BCS $\geq$ 3.5). This cut-off was based on a study by Daros et al. (2020) where it was determined that cows with BCS $\geq 3.5$ at dry-off lose condition during the dry period. No cows had BCS lower than 2.75. Parity was categorized at the time of dry-off as primiparous (i.e., those com- pleting their first lactation) and multiparous cows. For modeling, the variable previous 305-d milk yield was scaled (i.e., values were transformed into the SD from average lactation milk yield of enrolled cows).

\section{Statistical Analyses}

Statistical analyses were performed in RStudio version 1.2.5019 (RStudio Team, 2019) using R 3.5.3 (R Core Team, 2019). The annotated code and output were generated using the package 'rmarkdown' (Allaire et al., 2019). The data and statistical analysis documentation are available online at https://doi.org/10 .6084/m9.figshare.13567988.v1. The package 'tidyverse' (Wickham et al., 2019) was used to screen, wrangle, summarize, and visualize data.

Descriptive Statistics. To determine the correlation between feeding time and DMI during the dry period, we used Pearson's product moment correlation, which allowed for assessing correlation using paired data. To investigate the association between DMI and feeding time during the dry period, we also built linear mixed models using feeding time as the outcome variable, DMI as a fixed effect, and parity, previous 305-d milk yield, and trial diet (i.e., the study and dietary treatment individual cows were on during the dry period) as covariates, thus controlling for potential confounding variables. Repeated measures were accounted for by using cow as random intercept and day as random slope. A similar model was built to assess the relationship between $\triangle \mathrm{BCS}$ and the BCS at dry-off, using the same covariates and same random effect structure.

Inferential Statistics and Model Building Strategy. Because cows change their feeding behavior sometime in the $3 \mathrm{wk}$ before calving (Hayirli et al., 2002; Huzzey et al., 2007), we decided to split the data sets into 2 periods: early and late dry period, $\mathrm{d}-56$ to -22 and -21 to 0 in relation to calving, respectively. This allowed us to avoid having to include time-period

Table 1. Feeding behavior ${ }^{1}$ of 100 dry Holstein cows during d -56 to -22 (early dry period) and d -21 to 0 (late dry period) in relation to calving

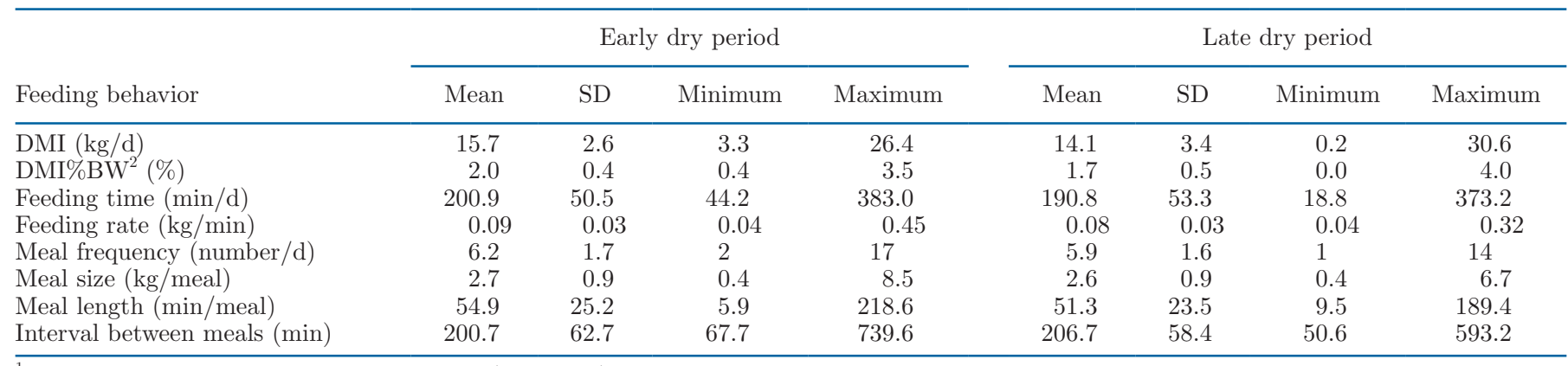

${ }^{1}$ Data originally collected by Havekes et al. (2020a,b,c).

${ }^{2} \mathrm{DMI} \% \mathrm{BW}=\mathrm{DMI}$ as a percentage of BW. 
related interaction terms in all models, which would decrease the interpretability of our findings. We also decided to adopt a different nomenclature than the often used, close-up and far-off period. The definition of close-up and far-off period may mean different things; this happens usually because the term close-up is related to changes in the diet offered and where cows are located (Mills et al., 2020). Because the cows in our study were kept in the same environment and were offered the same diet throughout the dry period, we decided to use a more neutral terminology.

To assess the association between BCS at dry-off and feeding behavior, we selected 3 behaviors: DMI, DMI\%BW, and feeding time. For each of the selected behaviors, we built a mixed linear regression model (package lme4; Bates et al., 2015) that allowed for controlling of known confounders (parity and previous 305-d milk yield) and differences in experimental design (trial diet). To control for repeated measures over time, we included cow as random intercept and day as random slope in all models. As per the default in the lme4 package, an unstructured variance-covariance matrix was used in the models. Interactions between BCS at dry-off and parity, and BCS at dry-off and day were included in all models, but later removed if $P>$ 0.05 . We assessed the validity of the models by graphically inspecting the distribution of the residuals from the random and fixed effects. All models demonstrated good homoscedasticity of residuals. Least squares means were generated from the models when necessary to help with data presentation and interpretation.

Mediation Analysis. The assumption for the mediation analysis was that BCS at dry-off influences $\triangle \mathrm{BCS}$ and that such cause is mediated by DMI (i.e., its causal pathway depends on cow's DMI during the dry period; Figure 1). To represent this scenario, we built a linear regression model to assess the association of BCS at dry-off and average DMI during the dry period with $\triangle$ BCS. In this model, we also included the effect of trial diet, parity, and previous 305-d milk yield to control for potential confounding effects. Similarly, we built a mediation model, this time only evaluating the association between average DMI during the dry period with BCS at dry-off, and controlled for the same set of covariates described above. A causal diagram of hypothetical associations among these variables is shown in Figure 1.

All mediation analyses were performed using the $\mathrm{R}$ package 'mediation' (Tingley et al., 2014). Using the 'mediate' function, we measured the direct and indirect effect (see Figure 1 for details) of BCS at dry-off on $\triangle B C S$. Results regarding the indirect effect reflected the effect explained by the mediation variable: average DMI during the dry period. The direct effect was the residual effect of BCS at dry-off on $\triangle \mathrm{BCS}$ that was not explained by the mediation proposed.

Because mediation analysis has strong assumptions, such as that there is no interaction between the causal variable and mediation variable, we assessed if the interaction between BCS at dry-off and average DMI during the dry period had any interaction effect on the outcome by using the function 'test.TMint' (Tingley et al., 2014). There was no detected interaction between variables $(P=0.17)$, thus we proceeded with the models without including the interaction term in the mediation analysis. Using the function 'medsens' (Tingley et al., 2014), a sensitivity analysis was conducted to measure the strength of hidden confounding variables which could invalidate the mediation effect.

\section{RESULTS}

\section{Descriptive Analysis}

Summarized feeding behavior data are presented in Table 1, and original values of selected feeding behaviors, split by BCS at dry-off category, are presented in Figure 2. Cows were nonlactating for an average of 42.5 $\mathrm{d}(\mathrm{SD}=5.0)$, and average BW at dry-off was $793.3 \mathrm{~kg}$ $(\mathrm{SD}=87.2)$. Average previous 305-d milk yield was $10,235 \mathrm{~kg}(\mathrm{SD}=1,625 \mathrm{~kg}$; range $7,160-14,210 \mathrm{~kg})$, and median parity at dry-off was 2 (range 1-6 lactations).

Body condition score at dry-off ranged from 2.75 to 4.25 , with median score at 3.25 points. Body condition score at dry-off categorization resulted in 61 cows labeled as not overconditioned (BCS <3.5) and 39 cows labeled as overconditioned (BCS $\geq 3.5$ ); however, only

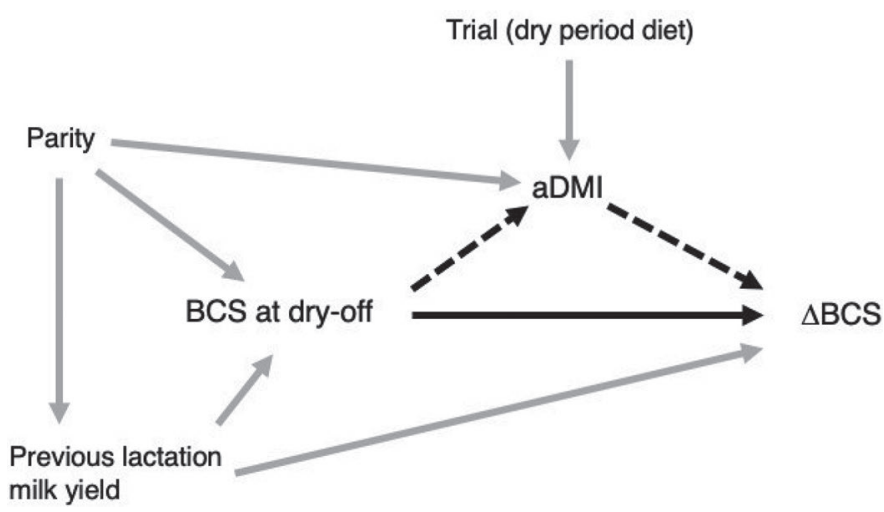

Figure 1. Causal diagram of the hypothetical causal web linking BCS at dry-off and body condition change over the dry period $(\triangle \mathrm{BCS})$. aDMI $=$ average dry matter intake during the dry period. Gray arrows represent the potential confounding effects controlled in the mediation analysis. Solid black arrow represents the average direct effect of BCS at dry-off on $\triangle \mathrm{BCS}$. Dashed black arrows represent the average indirect effect of BCS at dry-off on $\triangle \mathrm{BCS}$ that is mediated by DMI. 


\section{A

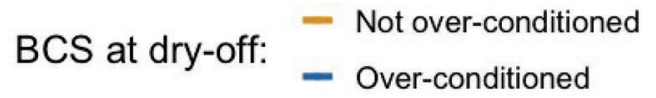

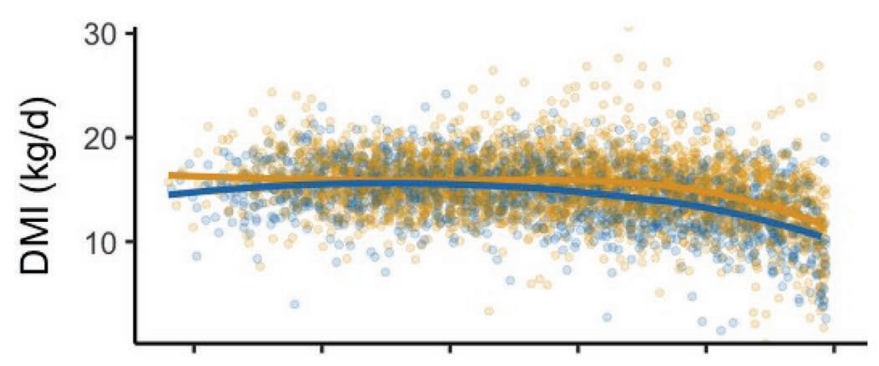

B

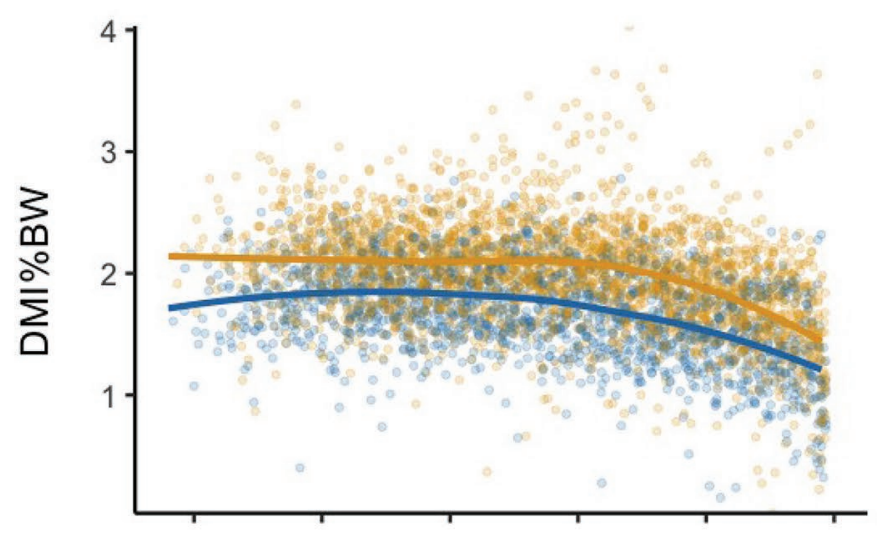

C

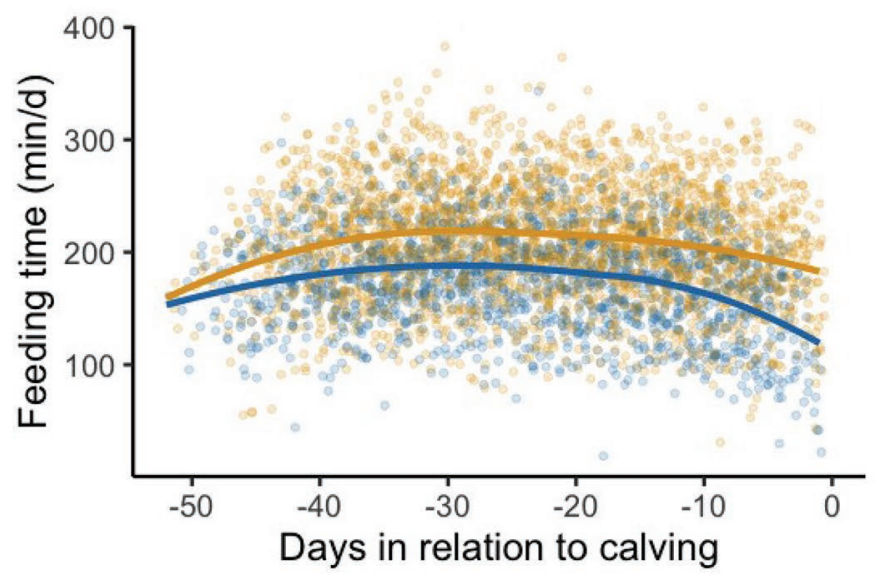

Figure 2. Original feeding behavior data (points) collected by Havekes et al. (2020a,b,c) of 100 Holstein dry cows housed in freestall pens, split by categories of BCS at dry-off. Dots represent cow's individual daily feeding behavior and were jittered using the 'geom_jitter' function (ggplot2 package; Wickham, 2016). Regression lines were estimated using the loess method from the 'geom_smooth' function (ggplot2 package; Wickham, 2016). Overconditioned = cows with BCS at dry-off $\geq 3.50$; not overconditioned $=$ cows with BCS at dry-off $<3.5$. $\mathrm{DMI} \% \mathrm{BW}=\mathrm{DMI}$ as a percentage of BW.
6 cows had $\mathrm{BCS} \geq 4.0$. Body condition score at dry-off was associated with $\triangle \mathrm{BCS}$; for each 1-point increase in BCS at dry-off, there was an associated loss of 0.31 BCS points $(\mathrm{SE}=0.06 ; P<0.01)$ during the dry period. Parity and previous 305-d milk yield were also associated with $\triangle \mathrm{BCS}$. Primiparous cows lost 0.12 more BCS points ( $\mathrm{SE}=0.05 ; P=0.02)$ than multiparous cows over the dry period. Cows with greater previous 305 -d milk yield also lost more BCS $(-0.05 \pm 0.03$ BCS points for each SD above the average previous 305-d milk yield; $P=0.03$ ) during the dry period compared with cows that produced less milk.

\section{Objective 1: Association Between Feeding Behavior and Body Condition at Dry-off}

Independent of parity, dry period diet, and previous 305-d milk yield, cows that were overconditioned at dry-off had lesser DMI and spent less time feeding during the early and late dry periods compared with not overconditioned cows (Figure 2). Least squares means of DMI during the early dry period for overconditioned and not overconditioned cows were $15.4 \pm 0.29$ versus $16.0 \pm 0.25 \mathrm{~kg} / \mathrm{d}(P=0.08$; Table 2$)$, respectively. When controlled for BW at dry-off, the difference was $1.84 \pm 0.05$ versus $2.14 \pm 0.04 \mathrm{DMI} \% \mathrm{BW}(P<0.01$; Table 3), respectively. Least squares means of feeding time during the early dry period followed the same trend; overconditioned cows spent $188 \pm 7.28 \mathrm{~min} / \mathrm{d}$ feeding, and not overconditioned cows spent $216 \pm 6.16$ $\mathrm{min} / \mathrm{d}$ feeding $(P<0.01$; Table 4$)$. No interactions between BCS at dry-off and parity $(P \geq 0.36)$ or between BCS at dry-off and day $(P \geq 0.51)$ were detected in any of the models for the early dry period.

During the late dry period, the differences between DMI and feeding time between the BCS categories followed the same pattern described for the early dry period with larger differences between groups. Overconditioned cows consumed $13.1 \pm 0.40 \mathrm{~kg} / \mathrm{d}$ of DM, and not overconditioned cows consumed $14.7 \pm 0.34 \mathrm{~kg} / \mathrm{d}$ of DM $(P<0.01$; Table 2$)$. Similarly, when controlling for $\mathrm{BW}$, overconditioned cows consumed $1.54 \pm 0.06$ $\mathrm{DMI} \% \mathrm{BW}$, and not overconditioned cows consumed $1.90 \pm 0.05$ DMI\%BW $(P<0.01$; Table 3$)$. Overconditioned cows also spent less time feeding compared with not overconditioned cows $(168 \pm 7.73$ vs. $205 \pm 6.55$ $\min / \mathrm{d} ; \quad P<0.01$; Table 4). No interactions between BCS at dry-off and parity $(P \geq 0.28)$ or between BCS at dry-off and day $(P \geq 0.16)$ were detected in any of the models for the late dry period.

There was no detected effect of parity on DMI, DMI\%BW, or feeding time during the early and late dry periods (Tables 2 to 4 ). Cows that produced more 
Table 2. Models $^{1}$ for the association between average DMI $(\mathrm{kg} / \mathrm{d})$ and BCS at dry-off during the early dry period (56 to $22 \mathrm{~d}$ before calving) and late dry period (21 to $0 \mathrm{~d}$ before calving), controlling for known confounders and experimental design

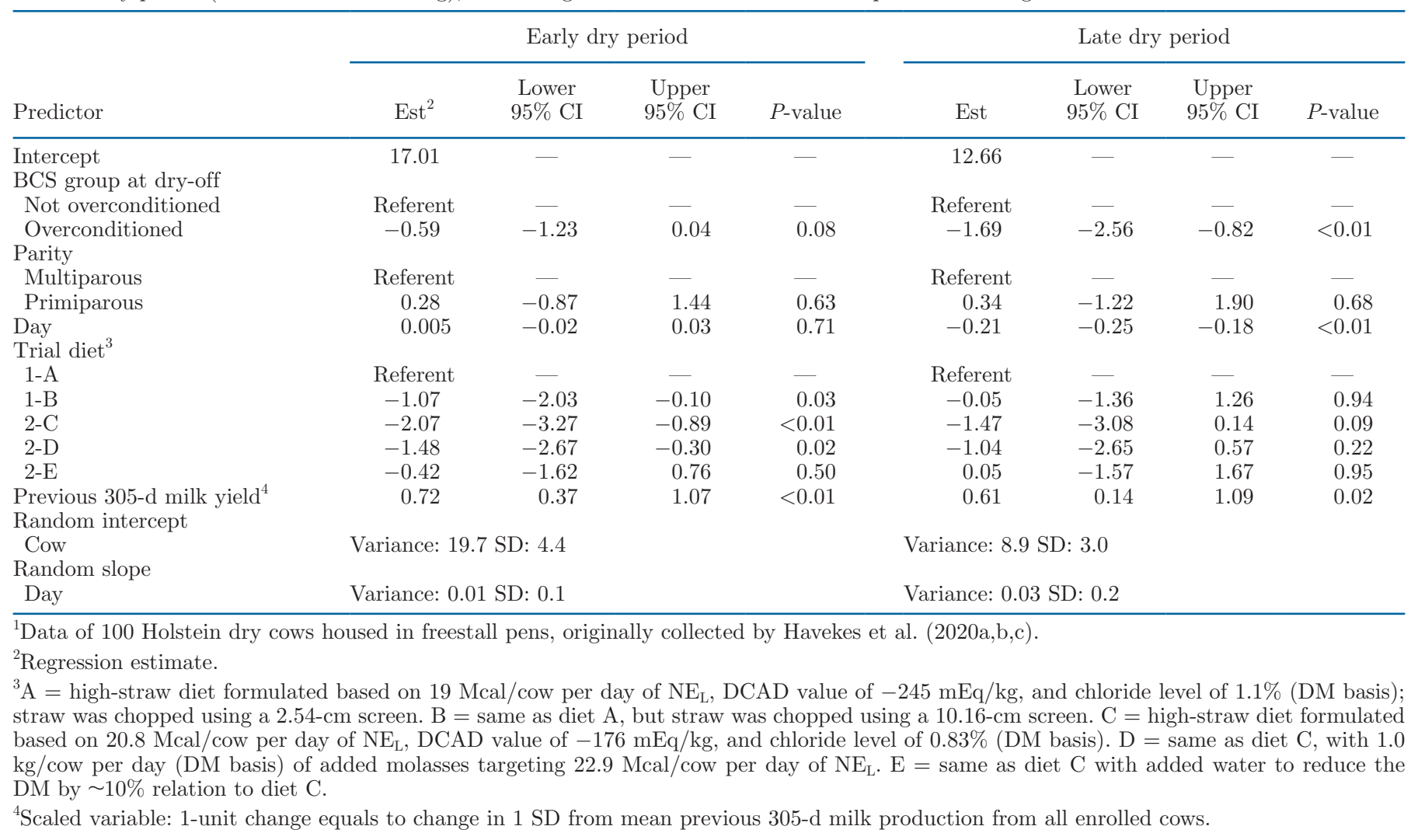

milk in the previous lactation had greater DMI in both the early and late dry periods (Table 2), but DMI\%BW and feeding time were not associated with previous 305-d milk production (Tables 3 and 4).

\section{Objective 2: Mediation Analysis-The Potential Causal Relationship Between DMI and $\triangle B C S$}

The proportion of the association between BCS at dry-off and $\triangle \mathrm{BCS}$ mediated by average DMI during the dry period was $16 \%$ (95\% CI: $5-39 \% ; P<0.01$ ). The direct effect of BCS at dry-off on $\triangle \mathrm{BCS}$ during the dry period remained statistically significant $(P<0.01)$ after inclusion of the mediation by average DMI during the dry period (Table 5).

\section{Objective 3: Associations Between Feeding Time and DMI During the Dry Period}

Feeding time and DMI correlated poorly during the early dry period $(\mathrm{r}=0.30 ; P<0.01)$ and moderately during the late dry period $(\mathrm{r}=0.57 ; P<0.01)$. After controlling for covariates over the early and late dry periods, for each $1-\mathrm{kg}$ increase in DMI, feeding time increased by $8.13 \pm 0.3 \mathrm{~min} / \mathrm{d}(P<0.01)$ and $9.19 \pm$ $0.2 \mathrm{~min} / \mathrm{d}(P<0.01)$, respectively.

\section{DISCUSSION}

Overall, our results demonstrated that cows that were overconditioned at dry-off spent less time eating and had lesser DMI throughout the dry period. These associations have been previously explored during the late dry period (Hayirli et al., 2002), but no researchers have identified these differences during the early dry period to our knowledge. Our results support the recommendation for avoiding obesity at the end of lactation to maintain greater DMI through the dry period and potentially improve transition-period health (Schuh et al., 2019).

Cows with greater body condition at dry-off were more likely to lose body condition during the dry period. This result aligns with previous studies in North America (Chebel et al., 2018; Daros et al., 2020); however, the potential mechanisms responsible for this association were not explored in these studies. Daros et al. (2020) reported that cows spending less than 4 h/d eating had greater BCS loss, but, unfortunately, 
Table 3. Models $^{1}$ for the association between average daily DMI as a percentage of BW (DMI\%BW) and BCS at dry-off during the early dry period (56 to $22 \mathrm{~d}$ before calving) and late dry period ( 21 to $0 \mathrm{~d}$ before calving) periods controlling for known confounders and experimental design

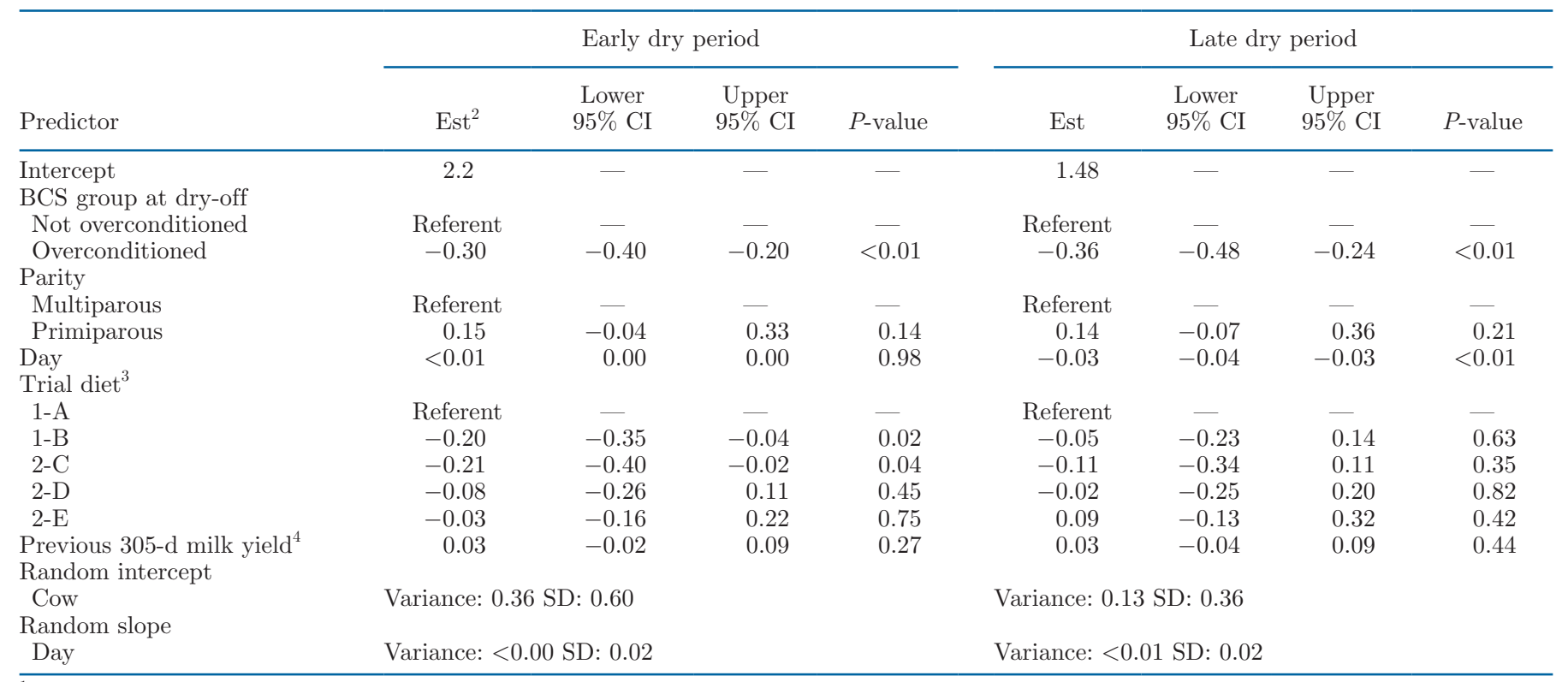

\footnotetext{
${ }^{1}$ Data of 100 Holstein dry cows housed in freestall pens, originally collected by Havekes et al. (2020a,b,c).

${ }^{2}$ Regression estimate.

${ }^{3} \mathrm{~A}=$ high-straw diet formulated based on $19 \mathrm{Mcal} / \mathrm{cow}$ per day of $\mathrm{NE}_{\mathrm{L}}$, DCAD value of $-245 \mathrm{mEq} / \mathrm{kg}$, and chloride level of $1.1 \%$ (DM basis); straw was chopped using a 2.54-cm screen. B = same as diet A, but straw was chopped using a 10.16-cm screen. C = high-straw diet formulated based on $20.8 \mathrm{Mcal} /$ cow per day of $\mathrm{NE}_{\mathrm{L}}$, $\mathrm{DCAD}$ value of $-176 \mathrm{mEq} / \mathrm{kg}$, and chloride level of $0.83 \%$ (DM basis). D = same as diet $\mathrm{C}$, with 1.0 $\mathrm{kg} /$ cow per day (DM basis) of added molasses targeting $22.9 \mathrm{Mcal} / \mathrm{cow}$ per day of $\mathrm{NE}_{\mathrm{L}} . \mathrm{E}=$ same as diet $\mathrm{C}$ with added water to reduce the $\mathrm{DM}$ by $\sim 10 \%$ relation to diet $\mathrm{C}$.

${ }^{4}$ Scaled variable: 1 -unit change equals to change in $1 \mathrm{SD}$ from mean previous 305-d milk production from all enrolled cows.
}

those researchers were not able to measure individual cow DMI. Our results suggested that DMI, however, is only partially responsible for BCS changes during the dry period. Changes in BCS during the period do not depend solely on environmental factors, such as feed availability, but also depend on internal physiological states (Roche et al., 2009). Because the proportion of $\triangle \mathrm{BCS}$ mediated by DMI was low $(16 \%)$ in the current study, it is likely that physiological mechanisms that play a role in regulating fat mobilization only partially influenced feed intake. According to the hepatic oxidation theory (Allen et al., 2009; Allen, 2020), excess lipid oxidation in the liver should decrease appetite. A physiological mechanism affecting BCS loss during this time may be low-grade inflammation observed during the precalving period (Bradford et al., 2015; Bradford and Swartz, 2020), which may be associated with stress (Bradford et al., 2015). Chronic inflammation that leads to insulin resistance is responsible for increased lipid mobilization. Related to this, overconditioned dry cows tend to have decreased insulin responsiveness (i.e., the effect of insulin in these cows are reduced; De Koster et al., 2015).
Researchers from New Zealand that studied grazing cows addressed a similar research question and measured precalving DMI for cows projected to have different BCS at the end of lactation (Roche et al., 2015). However, the results from Roche et al. (2015) contrast with those of the present study, where both groups of cows in that previous study gained BCS during the dry period and had similar levels of DMI during the dry period. These differences may be explained by the targeted BCS used by Roche et al. (2015). Using the formula described by Roche et al. (2004), their BCS groups would represent cows with 2.75 and 3.1 BCS points, respectively (Roche et al., 2015), which would have been both classified as not overconditioned in the present study. In a more recent study by Schuh et al. (2019) using indoor-housed German Holstein dairy cows, it was demonstrated that cows fed to be overconditioned at dry-off (BCS > 3.75) had lesser DMI during the late dry period compared with cows fed to be not overconditioned (BCS <3.5).

Mediation analysis is a powerful way to assess causality from observational data (Pearl, 2019). However, as in any predictive modeling study, the strength of 
Table 4. Models $^{1}$ for the association between average daily feeding time (min/d) and BCS at dry-off early dry period ( 56 to $22 \mathrm{~d}$ before calving) and late dry period (21 to $0 \mathrm{~d}$ before calving) periods controlling for known confounders and experimental design

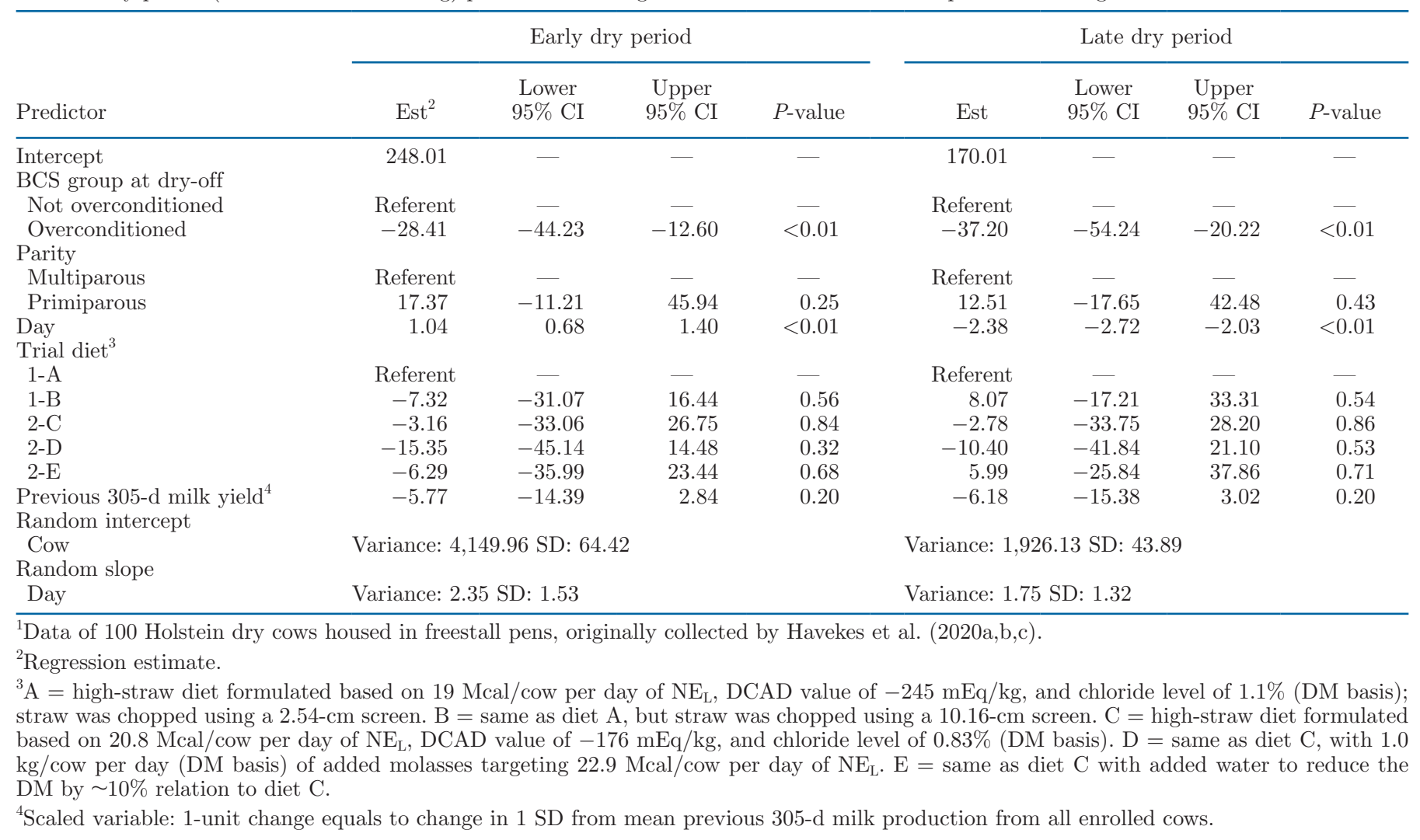

the results relies on the quality of the inputted data. Our results may have been stronger if we had a greater proportion of cows with BCS $>4.0$ at dry-off. We predicted that fatter cows would eat much less during the dry period, thus the proportion of body condition loss mediated by DMI would be greater. Because mediation analysis has strong assumptions, it is recommended to run sensitivity analysis on the results. Our sensitivity analysis data indicated that a confounder would have to explain $9 \%$ of the residual variance of the mediation model to cancel the mediated effect found in the original analysis. Given that we already included known confounders in our analysis, it is improbable that there was such a confounding variable.
Dry matter intake is highly dependent on energy and fiber content of the TMR (Hayirli et al., 2002). Because our data included groups of cows consuming different diets throughout the dry period, and those diet differences were accounted for in all of our models, we argue that our results can be interpreted more broadly. Moreover, in the original studies used for the current dataset, all diets were fed ad libitum and designed to meet the energy requirements of dry cows (Havekes et al., 2020a,b,c); restricting energy intake during the dry period may affect body condition changes (Roche et al., 2015).

The results regarding both $\mathrm{DMI}$ and $\mathrm{DMI} \% \mathrm{BW}$ were fairly consistent through the dry period. We recognize

Table 5. Mediation analysis ${ }^{1}$ of causal relationship between BCS at dry-off and body condition change over the dry period mediated by the average DMI during the dry period

\begin{tabular}{lcccc}
\hline & & Lower & Upper & \\
Effect & Estimate & $95 \%$ CI & $95 \%$ CI & $P$-value \\
\hline Average mediated effect & -0.05 & -0.12 & -0.02 & 0.0044 \\
Average direct effect & -0.27 & -0.41 & -0.15 & $<0.001$ \\
Total effect & -0.32 & -0.47 & -0.20 & $<0.001$ \\
Proportion mediated & 0.16 & 0.06 & 0.39 & 0.0044 \\
\hline
\end{tabular}

${ }^{1}$ Data of 100 Holstein dry cows housed in freestall pens, originally collected by Havekes et al. (2020a,b,c). 
that interpreting only DMI may be more appropriate, given that high BW does not necessarily equate to increased intake capacity; however, given the consistency of our results and the widespread use of DMI\%BW in the dairy literature (e.g., Pérez-Báez et al., 2019) we decided to keep both variables as a way to facilitate future comparisons between studies.

The associations between feeding time and DMI during both the early and late dry periods indicated that feeding time may be used to grossly estimate DMI. Some caution is warranted as the relationship between these behaviors was not strong; thus, we do not recommend using feeding time at the individual level, but rather for assessing group-level data, especially in large operations or large trials. In a previous study that measured DMI and feeding time over the transition period $(-14 \mathrm{~d}$ to $21 \mathrm{~d}$ in relation to calving), for cows diagnosed with or without metritis, the authors reported correlations $\left(\mathrm{R}^{2}\right)$ between feeding time and DMI during the final weeks prepartum of $0.36,0.41$, and 0.64 for healthy, mildly metritic, and metritic cows, respectively (Huzzey et al., 2007). We did not model the other feeding behaviors measured in Havekes et al. (2020 a,b,c), as they are intrinsically a function of either feeding time or DMI (Johnston and DeVries, 2018).

\section{CONCLUSIONS}

Overconditioned cows at dry-off demonstrated different feeding behavior throughout the dry period when compared with not overconditioned cows at dry-off. Specifically, overconditioned cows had lesser DMI and spent less time feeding overall. However, lesser DMI did not fully explain the relationship between greater BCS at dry-off and greater body condition loss during the period. Finally, feeding time correlated with DMI during the dry period, with a stronger association demonstrated in the late dry period.

\section{ACKNOWLEDGMENTS}

The projects these data were derived from were financially supported by a Natural Sciences and Engineering Research Council of Canada (NSERC; Ottawa, ON, Canada) Collaborative Research and Development Grant with Trouw Nutrition (Guelph, ON, Canada) and a Collaborative Research and Development Grant with Liquid Feeds International (Innerkip, ON, Canada), Quality Liquid Feeds (Dodgeville, WI), and the Ontario Agri-Food Innovation Alliance Research Program of the University of Guelph and the Ontario Ministry of Agriculture, Food, and Rural Affairs (Guelph, ON, Canada). The authors have not stated any conflicts of interest.

\section{REFERENCES}

Allaire, J.J., Y. Xie, J. McPherson, J. Luraschi, K. Ushey, A. Atkins, H. Wickham, J. Cheng, W. Chang, and R. Iannone. 2019. rmarkdown: Dynamic Documents for R. Accessed Jun. 10, 2019. https:// github.com/rstudio/rmarkdown.

Allen, M. S. 2020. Review: Control of feed intake by hepatic oxidation in ruminant animals: Integration of homeostasis and homeorhesis. Animal 14(S1):s55-s64. https://doi.org/10.1017/ S1751731119003215.

Allen, M. S., B. J. Bradford, and M. Oba. 2009. Board-invited review: The hepatic oxidation theory of the control of feed intake and its application to ruminants. J. Anim. Sci. 87:3317-3334. https://doi .org/10.2527/jas.2009-1779.

Bates, D., M. Mächler, B. Bolker, and S. Walker. 2015. Fitting linear mixed-effects models using lme4. J. Stat. Softw. 67. https://doi .org/10.18637/jss.v067.i01.

Bradford, B. J., and T. H. Swartz. 2020. Review: Following the smoke signals: Inflammatory signaling in metabolic homeostasis and homeorhesis in dairy cattle. Animal 14(S1):s144-s154. https://doi .org/10.1017/S1751731119003203.

Bradford, B. J., K. Yuan, J. K. Farney, L. K. Mamedova, and A. J. Carpenter. 2015. Invited review: Inflammation during the transition to lactation: New adventures with an old flame. J. Dairy Sci. 98:6631-6650. https://doi.org/10.3168/jds.2015-9683.

Chapinal, N., D. M. Veira, D. M. Weary, and M. A. G. Von Keyserlingk. 2007. Technical note: Validation of a system for monitoring individual feeding and drinking behavior and intake in group-housed cattle. J. Dairy Sci. 90:5732-5736. https://doi.org/ 10.3168/jds.2007-0331.

Chebel, R. C., L. G. D. Mendonça, and P. S. Baruselli. 2018. Association between body condition score change during the dry period and postpartum health and performance. J. Dairy Sci. 101:45954614. https://doi.org/10.3168/jds.2017-13732.

Daros, R. R., H. K. Eriksson, D. M. Weary, and M. A. G. von Keyserlingk. 2020. The relationship between transition period diseases and lameness, feeding time, and body condition during the dry period. J. Dairy Sci. 103:649-665. https://doi.org/10.3168/jds.2019 -16975 .

De Koster, J., M. Hostens, M. Van Eetvelde, K. Hermans, S. Moerman, H. Bogaert, E. Depreester, W. Van den Broeck, and G. Opsomer. 2015. Insulin response of the glucose and fatty acid metabolism in dry dairy cows across a range of body condition scores. J. Dairy Sci. 98:4580-4592. https://doi.org/10.3168/jds.2015-9341.

DeVries, T. J., M. A. G. von Keyserlingk, D. M. Weary, and K. A. Beauchemin. 2003. Measuring the feeding behavior of lactating dairy cows in early to peak lactation. J. Dairy Sci. 86:3354-3361. https://doi.org/10.3168/jds.S0022-0302(03)73938-1.

Elanco Animal Health. 1997. Appendix A: Body Condition Scoring in Cattle. Accessed Oct. 4, 2017. http://cdrf.org/wp-content/ uploads/2012/06/13_1_Body_condition_scoring.pdf.

Ghaffari, M. H., A. Jahanbekam, H. Sadri, K. Schuh, G. Dusel, C. Prehn, J. Adamski, C. Koch, and H. Sauerwein. 2019. Metabolomics meets machine learning: Longitudinal metabolite profiling in serum of normal versus overconditioned cows and pathway analysis. J. Dairy Sci. 102:11561-11585. https://doi.org/10.3168/ jds.2019-17114.

Grummer, R. R., D. G. Mashek, and A. Hayirli. 2004. Dry matter intake and energy balance in the transition period. Vet. Clin. North Am. Food Anim. Pract. 20:447-470. https://doi.org/10.1016/j .cvfa.2004.06.013.

Havekes, C. D., T. F. Duffield, A. J. Carpenter, and T. J. DeVries. 2020a. Effects of wheat straw chop length in high-straw dry cow diets on intake, health, and performance of dairy cows across the transition period. J. Dairy Sci. 103:254-271. https://doi.org/10 .3168/jds.2019-17033.

Havekes, C. D., T. F. Duffield, A. J. Carpenter, and T. J. DeVries. 2020 b. Moisture content of high-straw dry cow diets affects intake, health, and performance of transition dairy cows. J. Dairy Sci. 103:1500-1515. https://doi.org/10.3168/jds.2019-17557. 
Havekes, C. D., T. F. Duffield, A. J. Carpenter, and T. J. DeVries. 2020c. Effects of molasses-based liquid feed supplementation to a high-straw dry cow diet on feed intake, health, and performance of dairy cows across the transition period. J. Dairy Sci. 103:50705089. https://doi.org/10.3168/jds.2019-18085.

Hayirli, A., R. R. Grummer, E. V. Nordheim, and P. M. Crump. 2002. Animal and dietary factors affecting feed intake during the prefresh transition period in holsteins. J. Dairy Sci. 85:3430-3443. https://doi.org/10.3168/jds.S0022-0302(02)74431-7.

Huzzey, J. M., D. M. Veira, D. M. Weary, and M. A. G. von Keyserlingk. 2007. Prepartum behavior and dry matter intake identify dairy cows at risk for metritis. J. Dairy Sci. 90:3220-3233. https:/ /doi.org/10.3168/jds.2006-807.

Johnston, C., and T. J. DeVries. 2018. Short communication: Associations of feeding behavior and milk production in dairy cows. J. Dairy Sci. 101:3367-3373. https://doi.org/10.3168/jds.2017-13743.

Kaufman, E. I., S. J. LeBlanc, B. W. McBride, T. F. Duffield, and T. J. DeVries. 2016. Association of rumination time with subclinical ketosis in transition dairy cows. J. Dairy Sci. 99:5604-5618. https: //doi.org/10.3168/jds.2015-10509.

Mills, K. E., D. M. Weary, and M. A. G. Von Keyserlingk. 2020. Identifying barriers to successful dairy cow transition management. J. Dairy Sci. 103:1749-1758. https://doi.org/10.3168/jds.2018-16231.

Pearl, J. 2019. The seven tools of causal inference, with reflections on machine learning. Commun. ACM 62:54-60. https://doi.org/ $10.1145 / 3241036$.

Pérez-Báez, J., C. A. Risco, R. C. Chebel, G. C. Gomes, L. F. Greco, S. Tao, I. M. Thompson, B. C. do Amaral, M. G. Zenobi, N. Martinez, C. R. Staples, G. E. Dahl, J. A. Hernández, J. E. P. Santos, and K. N. Galvão. 2019. Association of dry matter intake and energy balance prepartum and postpartum with health disorders postpartum: Part I. Calving disorders and metritis. J. Dairy Sci. 102:9138-9150. https://doi.org/10.3168/jds.2018-15878.

R Core Team. 2019. R: A language and environment for statistical computing. R Foundation for Statistical Computing. https://www .r-project.org/.

Roche, J. R., P. G. Dillon, C. R. Stockdale, L. H. Baumgard, and M. J. VanBaale. 2004. Relationships among international body condition scoring systems. J. Dairy Sci. 87:3076-3079. https://doi.org/ 10.3168/jds.S0022-0302(04)73441-4.
Roche, J. R., N. C. Friggens, J. K. Kay, M. W. Fisher, K. J. Stafford, and D. P. Berry. 2009. Invited review: Body condition score and its association with dairy cow productivity, health, and welfare. J. Dairy Sci. 92:5769-5801. https://doi.org/10.3168/jds.2009-2431.

Roche, J. R., S. Meier, A. Heiser, M. D. Mitchell, C. G. Walker, M. A. Crookenden, M. V. Riboni, J. J. Loor, and J. K. Kay. 2015. Effects of precalving body condition score and prepartum feeding level on production, reproduction, and health parameters in pasture-based transition dairy cows. J. Dairy Sci. 98:7164-7182. https://doi.org/ 10.3168/jds.2014-9269.

RStudio Team. 2019. RStudio: Integrated Development Environment for R. http://www.rstudio.com/.

Schuh, K., H. Sadri, S. Häussler, L.A. Webb, C. Urh, M. Wagner, C Koch, J. Frahm, S. Dänicke, G. Dusel, and H. Sauerwein. 2019. Comparison of performance and metabolism from late pregnancy to early lactation in dairy cows with elevated v. normal body condition at dry-off. Animal 13:1478-1488. https://doi.org/10.1017/ S1751731118003385.

Tingley, D., T. Yamamoto, K. Hirose, L. Keele, and K. Imai. 2014. Mediation: R package for causal mediation analysis. J. Stat. Softw. 59. https://doi.org/10.18637/jss.v059.i05.

Wickham, H. 2016. Ggplot2: Elegant Graphics for Data Analysis. Springer-Verlag, New York, NY.

Wickham, H., M. Averick, J. Bryan, W. Chang, L. D. McGowan, R. François, G. Grolemund, A. Hayes, L. Henry, J. Hester, M. Kuhn, T. L. Pedersen, E. Miller, S. M. Bache, K. Müller, J. Ooms, D. Robinson, D. P. Seidel, V. Spinu, K. Takahashi, D. Vaughan, C. Wilke, K. Woo, and H. Yutani. 2019. Welcome to the tidyverse. J. Open Source Softw. 4:1686. https://doi.org/10.21105/joss.01686.

Wildman, E. E., G. M. Jones, P. E. Wagner, R. L. Boman, H. F. Troutt Jr., and T. N. Lesch. 1982. A Dairy cow body condition scoring system and its relationship to selected production characteristics. J. Dairy Sci. 65:495-501. https://doi.org/10.3168/jds .S0022-0302(82)82223-6.

\section{ORCIDS}

Ruan R. Daros @ (ttps://orcid.org/0000-0003-2331-1648 Trevor J. DeVries @ https://orcid.org/0000-0001-9364-2456 